\title{
SARS-CoV-2 Cases Reported From Long-Term Residential Facilities (Care Homes) in South Africa: A Retrospective Cohort Study
}

\section{Tracy Arendse ( $\nabla$ tracya@nicd.ac.za )}

National Institute for Communicable Diseases

\section{Beverley Cowper}

National Institute for Communicable Diseases

Cheryl Cohen

National Institute for Communicable Diseases

\section{Maureen Masha}

Right to Care

\section{Stefano Tempia}

University of the Witwatersrand

\section{Civil Legodu}

National Department of Social Development

\section{Sandhya Singh}

National Department of Health

\section{Tebogo Ratau}

Life Esidimeni

\section{Leon Geffen}

Samson Institute for Ageing Research

\section{Ansie Heymans}

National Department of Social Development

\section{Dane Coetzer}

National Department of Social Development

\section{Lucille Blumberg}

National Institute for Communicable Diseases; Right to Care

\section{Waasila Jassat}

National Institute for Communicable Diseases; Right to Care

\section{Research Article}

Keywords: Long term care facilities, outbreak, case fatality ratio, SARS-CoV-2, residents, staff 
Posted Date: December 3rd, 2021

DOI: https://doi.org/10.21203/rs.3.rs-1085908/v1

License: (c) (i) This work is licensed under a Creative Commons Attribution 4.0 International License. Read Full License 


\section{Abstract}

Background: Globally, long-term care facilities (LTCFs) experienced a large burden of deaths during the COVID-19 pandemic. The study aimed to describe the temporal trends as well as the characteristics and risk factors for mortality among residents and staff who tested positive for SARS-CoV-2 in selected LTCFs across South Africa.

Method: We analysed data reported to the DATCOV sentinel surveillance system by 45 LTCFs. Outbreaks in LTCFs were defined as large if more than one-third of residents and staff had been infected or there were more than 20 epidemiologically linked cases. Multivariable logistic regression was used to assess risk factors for mortality amongst LTCF residents.

Results: A total of 2,324 SARS-CoV-2 cases were reported from 5 March 2020 through 31 July 2021; 1,504 (65\%) were residents and 820 (35\%) staff. Among LTCFs, 6 reported sporadic cases and 39 experienced outbreaks. Of those reporting outbreaks, 10 (26\%) reported one and 29 (74\%) reported more than one outbreak. There were 48 (66.7\%) small outbreaks and 24 (33.3\%) large outbreaks reported. There were 30 outbreaks reported in the first wave, 21 in the second wave and 15 in the third wave, with 6 outbreaks reporting between waves. There were 1,259 cases during the first COVID-19 wave, 362 during the second wave, and 299 during the current third wave.

The case fatality ratio was $9 \%(138 / 1,504)$ among residents and $0.5 \%(4 / 820)$ among staff. On multivariable analysis, factors associated with SARS-CoV-2 mortality among LTCF residents were age 4059 years, $60-79$ years and $\geq 80$ years compared to $<40$ years and being a resident in a LTCF in Free State or Northern Cape compared to Western Cape. Compared to pre-wave 1, there was a decreased risk of mortality in wave 1 , post-wave 1 , wave 2 , post-wave 2 and wave 3.

Conclusion: The analysis of SARS-CoV-2 cases in sentinel LTCFs in South Africa points to an encouraging trend of decreasing numbers of outbreaks, cases and risk for mortality since the first wave. LTCFs are likely to have learnt from international experience and adopted national protocols, which include improved measures to limit transmission and administer early and appropriate clinical care.

\section{What The Article Reports}

The article reports data on 45 long-term care facilities (LTCFs) across South Africa. We report characteristics of both residents and staff infected with SARS-CoV-2 and describe the patterns of outbreaks across all reporting LTCFs. We also describe the trend in SARS-CoV-2 cases in LTCFs over the first, second and third waves in South Africa as well as the risk factors for mortality among LTCF residents and staff.

\section{Background}


The COVID-19 pandemic has greatly impacted on long-term care facilities (LTCFs), with outbreaks reported in many countries, affecting residents, staff and visitors. In the early period of the pandemic, countries in Europe and North America reported that a significant proportion of the total number of deaths due to the SARS-CoV-2 infection occurred in nursing homes. ${ }^{1,2}$ Once SARS-CoV-2 was introduced into an LTCF, it spread quickly resulting in significant morbidity, hospitalization, and mortality. ${ }^{3}$ Close living conditions put this population at risk for SARS-CoV-2 transmission. Advanced age and the presence of comorbid conditions among residents are risk factors for poor COVID-19 outcomes. ${ }^{1,4}$

The LTCF structure in South Africa is complex, fragmented and largely based on care of the elderly. South Africa provides old-age pensions to persons who are financially disadvantaged ${ }^{5}$, and all persons aged 60 and older are eligible for free primary healthcare, while access to hospital care is free only for those who are not able to afford it. ${ }^{6,7}$ In South Africa, there are an estimated 1,150 public and 1,000 private residential LTCFs for older persons. ${ }^{7}$ In addition to old age and retirement homes, many people are housed in congregate settings such as mental health and substance abuse facilities. The availability of LTCFs reflects urban-rural and historical racial divides, and most are managed by non-governmental and faith-based organisations. The standard of care in these facilities varies in quality. ${ }^{7}$

South Africa experienced a first wave of COVID-19 that peaked in July 2020, a second wave that peaked in January 2021 and a third wave that peaked in July 2021. By 9 September 2021, 2764931 SARS-CoV-2 cases and 87015 deaths had been reported. ${ }^{8}$

There is currently very little literature on the impact of COVID-19 in LTCFs in low-and middle-income countries (LMIC). It would be important to understand the nature of outbreaks occurring in LTCFs. The aim of this study was to describe the temporal trends in SARS-CoV-2 cases in LTCFs, as well as the demographics, characteristics and risk factors for mortality among residents and staff who tested positive for SARS-CoV-2 in 45 LTCFs across South Africa.

\section{Methods}

\section{Study design}

We implemented a retrospective cohort analysis of SARS-CoV-2 positive cases in LTCFs across South Africa from 5 March 2020 - 31 July 2021.

\section{Data source}

DATCOV, a hospital surveillance system for COVID-19 admissions, was initiated on 1 April 2020 and then subsequently expanded to include sentinel surveillance in LTCFs, implemented on 4 June 2020. Data are submitted by LTCFs that have agreed to report COVID-19 cases via the DATCOV LTCFs module. Participation in the LTCFs surveillance was voluntary and included a small number of sentinel facilities. When new facilities enrolled, they captured historical cases going back to their first recorded SARS-CoV-2 case. 


\section{Definitions of LTCFs}

A range of LTCFs or congregate settings were included in the sentinel surveillance, including old age homes $(21,46.7 \%)$, retirement villages $(11,24.4 \%)$, mental health facilities $(7,15.6 \%)$, substance abuse recovery facilities $(4,8.9 \%)$ and frail care facilities $2(4.4 \%)$. An old age home is defined as a LTCF where residents require daily care in a comfortable, safe and active environment. ${ }^{9}$ Retirement villages are defined as accommodating places that provide an independent lifestyle for those who do not need additional living assistance. ${ }^{10} \mathrm{~A}$ frail care centre is defined as a place giving care to those who are unable to care for themselves as a result of a motor-vehicle accident, physical disability, severe stroke or old age. ${ }^{9}$ Psychiatric and mental hospitals are defined as specialized hospital-based facilities that provide inpatient care and long-stay residential services for people with mental disorders. ${ }^{9}$ These facilities are usually independent and stand-alone, although they may have some links with the rest of the healthcare system. Substance abuse rehabilitation treatment facilities are defined as centres rectifying maladaptive behaviours and providing help with recovery from substance abuse disorders. ${ }^{11}$

\section{Study population}

The study population included all LTCF residents and staff in participating LTCFs in South Africa.

For the purpose of this study, we defined outbreaks in a LTCF as follows: ${ }^{12}$

- A sporadic case is defined as a single laboratory confirmed case of SARS-CoV-2 with 14-day period or longer before another laboratory-confirmed case.

- A small outbreak was defined as 2 to 20 confirmed SARS-CoV-2 cases or less than one third of residents or staff of a LTCF infected, within a 14-day period, with an epidemiological link.

- A large outbreak was defined as >20 confirmed SARS-CoV-2 cases or more than one third of residents or staff of a LTCF infected, within a 14-day period, with an epidemiologic link.

The wave periods were defined by the case incidence data with a national weekly incidence of 30 cases per $100,000^{13}$ as cut off for start and end of wave periods:

- Pre-wave-1: epidemiologic weeks 10 - 23 of 2020 (1 March - 6 June 2020)

- First wave: epidemiologic weeks $24-34$ of 2020 (7 June - 22 August 2020)

- Post-wave 1: epidemiologic weeks 35 - 46 of 2020 (23 August - 14 November 2020)

- Second wave: epidemiologic weeks 47 of 2020 - week 5 of 2021 (15 November 2020 - 06 February 2021)

- Post-wave 2: epidemiologic weeks 6 - 19 of 2021 (7 February - 8 May 2021)

- Third wave: epidemiologic weeks $20-30$ of 2021 (09 May 2021 - 31 July 2021)

\section{Data collection and management}


Data collection was either through direct entry onto the DATCOV online platform or through importation of electronic data via bulk-upload for LTCFs that did not have a stable internet connection. If a resident or staff member tested positive for SARS-CoV-2, the dedicated data entry clerk in the LTCF would complete the electronic data form. The case reporting form was adapted from the World Health Organisation (WHO) SARS-CoV-2 case reporting tool and included basic demographic data, pre-existing health conditions and outcomes (died and recovered).

Data imports contained validation checks to identify data errors. Routine checks were performed on all data. Missing and discrepant data were followed up telephonically or by email with the submitting person.

COVID-19 mortality was defined as a death related to SARS-CoV-2 that occurred at the LTCF or while being admitted to hospital, excluding deaths that occurred due to other causes or after recovery. A COVID19 death is defined for surveillance purposes as a death due to a clinically compatible illness, in a confirmed COVID-19 case, unless there is a clear alternative cause of death that cannot be related to COVID disease (e.g. trauma), with no period of complete recovery from COVID-19 between illness and death. ${ }^{14}$

\section{Data analysis}

Descriptive statistics including frequencies and percentages were used for categorical variables, while for continuous variables a median and interquartile range (IQR) were calculated.

A random effect multivariable logistic regression model was used to assess risk factors for mortality amongst LTCF residents with laboratory-confirmed SARS-CoV2. Age, race, sex and comorbidities (hypertension, diabetes mellitus, chronic cardiac disease, asthma, other chronic respiratory disease, chronic renal disease, malignancy in the past five years, HIV, past and current tuberculosis), smoking, obesity, province, type of LTCF, and wave period, were included in models assessing risk factors for COVID-19 mortality. We assessed all variables that were significant at $p<0.2$ on univariate analysis and dropped non-significant factors $(p \geq 0.05)$ with manual backward elimination. Pairwise interactions were assessed by inclusion of product terms for all variables remaining in the final multivariable additive model. We also reported the univariate association of all covariates evaluated in the analyses described above to the main outcome (mortality in individuals with COVID-19). The statistical analysis was implemented using Stata 15 (Stata Corp ${ }^{\circledR}$, College Station, Texas, USA).

\section{Ethical considerations}

The data used for this study were de-identified to ensure confidentiality. All personal information of the residents and staff, concerning health status, treatment or stay in a health establishment, were kept confidential and stored in a secure server. For analysis, patient identifiers were de-linked from other data and stored separately. Ethical approval for this study was obtained from the University of the 
Witwatersrand Human Research Ethics Committee (M160667). The study was performed in accordance with all relevant ethical guidelines and regulations and with good clinical practice.

Disease surveillance is a critical function of the NICD as a statutory body in South Africa. The NICD has a national mandate to conduct COVID-19 hospital surveillance. The amended regulations that accompany the declaration of a national disaster (Disaster Management Act 2002), provides for healthcare institutions to submit data to NICD on notifiable medical conditions, which includes COVID-19. This encompasses the submission of patient details, their treatment and outcomes. In this case individual consent is therefore waived.

\section{Results}

As of 31 July 2021, 2,324 SARS-CoV-2 cases were reported from 45 LTCFs in eight of nine provinces in South Africa. Psychiatric facilities reported the most cases (918, 39.5\%), followed by old age homes (420, $18.1 \%)$, retirement villages $(405,17.4 \%)$, substance abuse recovery facilities $(391,16.8 \%)$ and frail care facilities $(190,8.2 \%)$.

Psychiatric facilities reported cases in 657/1,504 (43.8\%) of residents and 261/820 (31.8\%) of staff; old age homes reported 269/1,504 (17.9\%) residents and 151/1,504 (18.4\%) staff infected, substance abuse recovery centres $241 / 1,504(16.0 \%)$ residents and 150/820 (18.3\%) staff infected, retirement villages $214 / 1,504(14.2 \%)$ residents and 191/820 (23.3\%) staff infected; and frail care centres 123/1,504 (8.2\%) residents and $67 / 820(8.2 \%)$ staff infected (Figure 1a).

\section{Temporal trend in LTCF SARS-CoV-2 cases in LTCFs.}

The proportion of cases in staff decreased over the surveillance period (Figure 1b).

Among all SARS-CoV-2 cases from sentinel LTCFs, 1,259 (54.2\%) were reported during the first wave, 362 (15.6\%) during the second wave and 299 (12.9\%) during the third wave (Figure 2).

\section{Pattern of outbreaks in LTCFs}

There were varying patterns of outbreaks among LTCFs, with six (13.3\%) reporting no outbreaks (only sporadic cases), 10 (22.2\%) reporting one outbreak and 29 (64.5\%) reporting more than one outbreak (Supplementary Table 1). The six (13.3\%) LTCFs reporting sporadic SARS-CoV-2 positive cases included four old age homes and two retirement villages (Supplementary Figure 1). There were 48 (66.7\%) small outbreaks and 24 (33.3\%) large outbreaks reported (Supplementary Figure 2). The 24 (61.5\%) LTCFs that reported large SARS-CoV-2 outbreaks included $8(33.3 \%)$ retirement villages, $6(25.0 \%)$ psychiatric facilities, 5 (20.8\%) old age homes, $4(16.7 \%)$ substance abuse recovery centres and 1 (4.0\%) frail care centre (Supplementary Figure 3). There were 30 outbreaks reported in wave 1, 21 in wave 2 and 15 in wave 3, while 6 outbreaks were reported between waves.

\section{Demographic and clinical characteristics of SARS-CoV-2 cases among LTCF residents}


The median age of COVID-19 cases among residents was 56 years (IQR 38-73) and 812/1,504 (54.0\%) were male (Table 1). Of the 1,501 (99.8\%) residents for whom race was known, 734 (49.0\%) were Black African, 610 (40.6\%) were White, 101 (6.7\%) were Coloured and 56 (3.7\%) were Indian. Among 1,473 (97.9\%) residents for whom there were data on comorbidities, $274(18.6 \%)$ had comorbid conditions. Of these, 191 (69.7\%) had one comorbid condition, 60 (21.9\%) had two comorbid conditions and 23 (8.3\%) had three or more comorbid conditions. The most common comorbid conditions among residents were hypertension (194, 15.2\%), diabetes mellitus (64,4.5\%) and chronic cardiac disease $(48,3.4 \%)$. Of the 1,504 SARS-CoV-2 positive residents with outcomes, 1,308 (87.0\%) recovered, 34 (2.3\%) were active cases and $137(9.1 \%)$ had died, giving a case fatality ratio (CFR) of $9.1 \%$. The CFR excluding active cases amongst residents was 137/1,445 (9.5\%).

\section{Demographic and clinical characteristics of SARS-CoV-2 cases among LTCF staff}

The median age of COVID-19 admissions amongst staff was 42 years (IQR 35-51) and 705/820 (86.0\%) were female (Table 1). Of the 767 (93.5\%) staff for whom race was known, 640 (83.4\%) were Black African, 79 (10.3\%) were Coloured, 8 (1.0\%) were Indian and 40 (5.2\%) were White. Among 793 (96.7\%) staff for whom there were data on comorbidities, 104 (13.1\%) had comorbid conditions. Of these, 82 (78.8\%) had one comorbid condition, $20(18.2 \%)$ had two and three $(2.9 \%)$ had three or more comorbid conditions. The most common comorbid conditions among staff were hypertension 69 (8.7\%), diabetes mellitus 28 (3.5\%), HIV 15 (1.9\%) and asthma 14 (1.8\%). Of the 820 SARS-CoV-2 positive staff with outcomes, $762(92.9 \%)$ cases recovered, $53(6.5 \%)$ were active cases and $4(0.5 \%)$ had died, giving a case fatality ratio (CFR) of $0.5 \%$. The CFR excluding active cases amongst staff was $4 / 766(0.5 \%)$. 
Table 1

Characteristics of SARS-CoV-2 cases amongst residents and staff in LTCFs, 5 March 2020 - 31 July $2021(n=2,324)$.

\begin{tabular}{|c|c|c|}
\hline \multirow[t]{3}{*}{ Characteristic } & Residents & Staff \\
\hline & $N=1,504$ & $N=820$ \\
\hline & $\mathrm{n}(\%)$ & $\mathrm{n}(\%)$ \\
\hline \multicolumn{3}{|l|}{ Age group } \\
\hline $0-39$ years & $400(26.6)$ & $329(40.1)$ \\
\hline $40-59$ years & $423(28.1)$ & $444(54.2)$ \\
\hline 60-79 years & $456(30.3)$ & $47(5.7)$ \\
\hline 80 years & $225(15.0)$ & $0(0)$ \\
\hline \multicolumn{3}{|l|}{ Sex } \\
\hline Female & $692(46.0)$ & $705(86.0)$ \\
\hline Male & $812(54.0)$ & $115(14.0)$ \\
\hline \multicolumn{3}{|l|}{ Race } \\
\hline White & $610(40.6)$ & $40(5.2)$ \\
\hline Black African & $734(48.9)$ & $640(83.4)$ \\
\hline Mixed & $101(6.7)$ & 79 (10.3) \\
\hline Indian & $56(3.7)$ & $8(1.1)$ \\
\hline \multicolumn{3}{|l|}{ Comorbidities } \\
\hline Hypertension & $194(13.2)$ & $69(8.7)$ \\
\hline Diabetes & $64(4.3)$ & $28(3.5)$ \\
\hline Chronic Cardiac Disease & $48(3.3)$ & $1(0.1)$ \\
\hline Asthma/Chronic Pulmonary Disease & $27(1.8)$ & $14(1.8)$ \\
\hline Chronic Renal Disease & $8(0.5)$ & $0(0)$ \\
\hline Malignancy & $9(0.6)$ & $3(0.4)$ \\
\hline HIV & $29(2.0)$ & $15(2.0)$ \\
\hline Active Tuberculosis & 0 & $1(0.1)$ \\
\hline Past tuberculosis & $1(0.1)$ & 0 \\
\hline Facility type & & \\
\hline
\end{tabular}




\begin{tabular}{|lll|}
\hline Characteristic & Residents & Staff \\
& $\mathbf{N}=1,504$ & $\mathbf{N}=820$ \\
& $\mathbf{n}(\%)$ & $\mathbf{n}(\%)$ \\
\hline Substance abuse recovery centre & $241(16.0)$ & $150(18.3)$ \\
\hline Frail care centre & $123(8.2)$ & $67(8.2)$ \\
\hline Old age home & $269(17.9)$ & $151(18.4)$ \\
\hline Psychiatric/Mental & $657(43.7)$ & $261(31.8)$ \\
\hline Retirement village & $241(14.2)$ & $150(23.3)$ \\
\hline Wave period & & \\
\hline Pre-wave 1 & $118(7.9)$ & $118(14.4)$ \\
\hline Wave 1 & $811(53.9)$ & $448(54.6)$ \\
\hline Post-wave 1 & $60(4.0)$ & $78(9.5)$ \\
\hline Wave 2 & $241(16.0)$ & $121(14.7)$ \\
\hline Post-wave 2 & $20(1.3)$ & $10(1.2)$ \\
\hline Wave 3 & $254(16.9)$ & $45(5.5)$ \\
\hline Outcome & & \\
\hline Recovered & $1,366(88.4)$ & $816(93.0)$ \\
\hline Died & $138(9.3)$ & $4(0.5)$ \\
\hline
\end{tabular}

\section{Temporal trend in SARS-CoV-2 deaths in LTCFs}

The number of SARS-CoV-2 deaths and CFR among residents in the various epidemic periods were $21 / 115(18.3 \%)$ in pre-wave $1 ; 70 / 793$ (8.8\%) during wave $1 ; 5 / 60$ (8.3\%) during post-wave $1 ; 25 / 241$ (10.4\%) during wave 2, 2/18 (11.1\%) during post-wave 2 and 15/218 (6.9\%) during wave 3. (Figure 3 ).

The number of SARS-CoV-2 deaths and CFR among staff in the various pandemic periods were 1/91 (1.1\%) during pre-wave $1 ; 2 / 438(0.5 \%)$ during wave 1 ; and $1 / 112(0.9 \%)$. No deaths occured in satff during post-wave 1, post-wave 2 and wave 3 .

Among residents the CFR was 46/252 (18.3\%) in old age homes, 15/112 (13.4\%) in frail care centres; $21 / 389(10.5 \%)$ in retirement villages; $47 / 649(7.2 \%)$ in psychiatric facilities; and 9/232 (3.9\%) in substance abuse recovery centres. 
Of the four staff $(0.5 \%)$ who died, two each were female and male. The median age was 48.5 years (IQR 44.5-57.0). One female had hypertension and diabetes mellitus. The remaining three individuals who died did not have any reported comorbidities. Each of the four deaths occurred in an old age home, psychiatric facility, retirement village and a substance abuse recovery centre.

\section{Factors associated with SARS-CoV-2 mortality in residents}

On multivariable analysis, factors associated with SARS-CoV-2 mortality among LTCF residents were age 40-59 years (aOR 2.4, 95\% Cl 1.0-5.5), 60-79 years (aOR 7.6, 95\% Cl 3.6-16.5) and $\geq 80$ years (aOR 18.2, $95 \% \mathrm{Cl} 8.1-41.2)$ compared to $<40$ years; and being a resident in a LTCF in Free State (aOR 4.2, 95\% Cl 1.412.8) or Northern Cape (aOR 3.8, 95\% Cl 1.2-12.6) compared to Western Cape (Table 2). Compared to prewave 1, there was a decreased risk of mortality in wave 1 (aOR $0.3,95 \% \mathrm{Cl} 0.1-0.9$ ), post-wave 1 (aOR 0.2, $95 \% \mathrm{Cl} 0.05-0.8$ ), wave 2 (aOR 0.3, 95\% Cl 0.1-1.0), post-wave 2 (aOR 0.1, 95\% $\mathrm{Cl} 0.02-0.9$ ) and wave 3 (aOR 0.2, 95\% Cl 0.006-0.6). 
Table 2

Multivariable analysis of factors associated with SARS-CoV-2 mortality among LTCF residents, South Africa, 5 March 2020- 31 July 2021 ( $n=1,504)$.

\begin{tabular}{|c|c|c|c|c|c|}
\hline Characteristic & $\begin{array}{l}\text { Case fatality } \\
\text { ratio } \\
\mathrm{n} / \mathrm{N}(\%)\end{array}$ & $\begin{array}{l}\text { Unadjusted } \\
\text { odds ratio } \\
(95 \% \mathrm{Cl})\end{array}$ & p-value & $\begin{array}{l}\text { Adjusted } \\
\text { odds ratio } \\
(95 \% \mathrm{Cl})\end{array}$ & p-value \\
\hline \multicolumn{6}{|l|}{ Age group } \\
\hline $0-39$ years & $8 / 400(2.0)$ & Reference & & Reference & \\
\hline 40-59 years & $20 / 423(4.7)$ & $2.4(1.1-5.6)$ & 0.036 & $2.4(1.0-5.5)$ & 0.038 \\
\hline 60-79 years & $\begin{array}{l}58 / 456 \\
(12.7)\end{array}$ & $7.1(3.4-15.2)$ & $\leq 0.001$ & $\begin{array}{l}7.6(3.6- \\
16.5)\end{array}$ & $\leq 0.001$ \\
\hline$\geq 80$ years & $\begin{array}{l}52 / 225 \\
(23.1)\end{array}$ & $14.7(6.8-31.7)$ & $\leq 0.001$ & $\begin{array}{l}18.2(8.1- \\
41.2)\end{array}$ & $\leq 0.001$ \\
\hline Sex & $59 / 692(8.7)$ & Reference & & & \\
\hline \multicolumn{6}{|l|}{ Female } \\
\hline Male & $78 / 812(9.9)$ & $1.1(0.8-1.6)$ & 0.531 & & \\
\hline \multicolumn{6}{|l|}{ Race/Ethnicity } \\
\hline Black & $47 / 734(6.4)$ & Reference & & & \\
\hline Coloured & 8/101 (7.9) & $1.3(0.6-2.8)$ & 0.572 & & \\
\hline White & $\begin{array}{l}74 / 610 \\
(12.1)\end{array}$ & $2.8(1.3-6.2)$ & 0.008 & & \\
\hline Indian & $9 / 56(16.1)$ & $2.1(1.4-3.0)$ & $\leq 0.001$ & & \\
\hline \multicolumn{6}{|l|}{ Type of LTCF } \\
\hline Substance Abuse & $9 / 241(3.7)$ & Reference & & & \\
\hline Frail Care Centre & $\begin{array}{l}16 / 123 \\
(13.0)\end{array}$ & $3.9(1.7-9.0)$ & 0.002 & & \\
\hline Old age home & $\begin{array}{l}45 / 269 \\
(16.7)\end{array}$ & $5.1(2.5-11.0)$ & $\leq 0.001$ & & \\
\hline Psychiatric/Mental & $47 / 657$ (7.2) & $2.0(0.9-4.1)$ & 0.065 & & \\
\hline Retirement village & $21 / 214(9.8)$ & $2.8(1.3-6.3)$ & 0.012 & & \\
\hline \multicolumn{6}{|l|}{ Wave period } \\
\hline Pre-wave 1 & $\begin{array}{l}21 / 118 \\
(18.3)\end{array}$ & Reference & 0.002 & Reference & 0.023 \\
\hline Wave 1 & $70 / 811(8.6)$ & $0.4(0.3-0.7)$ & & $0.3(0.1-0.9)$ & \\
\hline
\end{tabular}




\begin{tabular}{|c|c|c|c|c|c|}
\hline Characteristic & $\begin{array}{l}\text { Case fatality } \\
\text { ratio } \\
\mathrm{n} / \mathrm{N}(\%)\end{array}$ & $\begin{array}{l}\text { Unadjusted } \\
\text { odds ratio } \\
(95 \% \mathrm{Cl})\end{array}$ & p-value & $\begin{array}{l}\text { Adjusted } \\
\text { odds ratio } \\
(95 \% \mathrm{Cl})\end{array}$ & p-value \\
\hline Post-wave 1 & $5 / 60(8.3)$ & $0.4(0.1-1.1)$ & 0.099 & $\begin{array}{l}0.2(0.05- \\
0.8)\end{array}$ & 0.027 \\
\hline Wave 2 & $\begin{array}{l}25 / 241 \\
(10.4)\end{array}$ & $0.5(0.3-1.0)$ & 0.051 & $0.3(0.1-1.0)$ & 0.059 \\
\hline Post-wave 2 & $2 / 20(10.0)$ & $0.5(0.1-2.4)$ & 0.394 & $\begin{array}{l}0.1(0.02- \\
0.9)\end{array}$ & 0.035 \\
\hline Wave 3 & $15 / 254(5.9)$ & $0.3(0.1-0.6)$ & 0.001 & $\begin{array}{l}0.2(0.06- \\
0.6)\end{array}$ & 0.004 \\
\hline \multicolumn{6}{|l|}{ Comorbid condition } \\
\hline 1 comorbid condition & $\begin{array}{l}22 / 191 \\
(11.5)\end{array}$ & Reference & & & \\
\hline 2 comorbid conditions & $10 / 60(16.7)$ & $1.5(0.7-3.5)$ & 0.300 & & \\
\hline$\geq 3$ comorbid conditions & $5 / 24(20.8)$ & $2.0(0.7-6.0)$ & 0.202 & & \\
\hline $\begin{array}{l}\text { Hypertension } \\
\text { No } \\
\text { Yes }\end{array}$ & $\begin{array}{l}108 / 1,280 \\
(8.4) \\
27 / 194 \\
(13.9)\end{array}$ & $\begin{array}{l}\text { Reference } \\
1.8(1.1-2.8)\end{array}$ & 0.015 & & \\
\hline $\begin{array}{l}\text { Diabetes mellitus } \\
\text { No } \\
\text { Yes }\end{array}$ & $\begin{array}{l}123 / 1,410 \\
(8.7) \\
12 / 64(18.8)\end{array}$ & $\begin{array}{l}\text { Reference } \\
2.4(1.3-4.6)\end{array}$ & 0.008 & & \\
\hline $\begin{array}{l}\text { Chronic cardiac disease } \\
\text { No } \\
\text { Yes }\end{array}$ & $\begin{array}{l}132 / 1,466 \\
(9.0) \\
3 / 8(37.5)\end{array}$ & $\begin{array}{l}\text { Reference } \\
2.7(1.3-5.6)\end{array}$ & 0.006 & & \\
\hline $\begin{array}{l}\text { Asthma/Chronic } \\
\text { pulmonary disease } \\
\text { No } \\
\text { Yes }\end{array}$ & $\begin{array}{l}134 / 1,450 \\
(9.2) \\
1 / 24(4.2)\end{array}$ & $\begin{array}{l}\text { Reference } \\
0.4(0.1-3.1)\end{array}$ & 0.407 & & \\
\hline $\begin{array}{l}\text { Chronic renal disease } \\
\text { No } \\
\text { Yes }\end{array}$ & $\begin{array}{l}132 / 1,466 \\
(9.0) \\
3 / 8(37.5)\end{array}$ & $\begin{array}{l}\text { Reference } \\
6.1(1.4-25.74)\end{array}$ & 0.014 & & \\
\hline
\end{tabular}




\begin{tabular}{|c|c|c|c|c|c|}
\hline Characteristic & $\begin{array}{l}\text { Case fatality } \\
\text { ratio } \\
\mathrm{n} / \mathrm{N}(\%)\end{array}$ & $\begin{array}{l}\text { Unadjusted } \\
\text { odds ratio } \\
(95 \% \mathrm{Cl})\end{array}$ & p-value & $\begin{array}{l}\text { Adjusted } \\
\text { odds ratio } \\
(95 \% \mathrm{Cl})\end{array}$ & p-value \\
\hline $\begin{array}{l}\text { Malignancy } \\
\text { No } \\
\text { Yes }\end{array}$ & $\begin{array}{l}134 / 1,465 \\
(9.2) \\
1 / 9(11.1)\end{array}$ & $\begin{array}{l}\text { Reference } \\
1.2(0.2-10.0)\end{array}$ & 0.839 & & \\
\hline $\begin{array}{l}\text { HIV } \\
\text { No } \\
\text { Yes }\end{array}$ & $\begin{array}{l}133 / 1,445 \\
(9.2) \\
2 / 29(6.9)\end{array}$ & $\begin{array}{l}\text { Reference } \\
0.7(0.2-3.1)\end{array}$ & 0.671 & & \\
\hline $\begin{array}{l}\text { Active Tuberculosis } \\
\text { No } \\
\text { Yes }\end{array}$ & $\begin{array}{l}135 / 1,474 \\
(9.2) \\
0\end{array}$ & $\begin{array}{l}\text { Reference } \\
1\end{array}$ & - & & \\
\hline $\begin{array}{l}\text { Past Tuberculosis } \\
\text { No } \\
\text { Yes }\end{array}$ & $\begin{array}{l}135 / 1,473 \\
(9.2) \\
0\end{array}$ & $\begin{array}{l}\text { Reference } \\
1\end{array}$ & - & & \\
\hline Smoking & $38 / 412(9.2)$ & Reference & 0.461 & & \\
\hline Never smoked & $8 / 70(11.4)$ & $1.3(0.6-2.9)$ & 0.001 & & \\
\hline $\begin{array}{l}\text { Former smoker } \\
\text { Current smoker }\end{array}$ & $2 / 209(1.0)$ & $0.09(0.02-0.4)$ & & & \\
\hline Province & & & & & \\
\hline Western Cape & $14 / 64(21.8)$ & Reference & & Reference & \\
\hline Eastern Cape & $12 / 132(9.1)$ & $0.4(0.2-0.8)$ & 0.016 & $1.3(0.5-3.1)$ & 0.620 \\
\hline Free State & $\begin{array}{l}30 / 225 \\
(13.3)\end{array}$ & $0.5(0.3-1.1)$ & 0.097 & $\begin{array}{l}4.2(1.4- \\
12.8)\end{array}$ & 0.012 \\
\hline Gauteng & $26 / 430(6.1)$ & $0.2(0.1-0.5)$ & $\leq 0.001$ & $1.5(0.5-4.7)$ & 0.441 \\
\hline KwaZulu-Natal & $27 / 305$ (8.9) & $0.3(0.2-0.7)$ & 0.004 & $1.6(0.5-5.0)$ & 0.380 \\
\hline Limpopo & 2/35 (5.7) & $0.2(0.04-1.1)$ & 0.052 & $1.5(0.2-9.6)$ & 0.655 \\
\hline Mpumalanga & 10/99 (10.1) & $0.4(0.2-0.9)$ & 0.043 & $1.5(0.4-4.8)$ & 0.544 \\
\hline Northern Cape & $17 / 214(7.9)$ & $0.3(0.1-0.7)$ & 0.003 & $\begin{array}{l}3.8(1.2- \\
12.6)\end{array}$ & 0.028 \\
\hline
\end{tabular}




\section{Discussion}

The DATCOV sentinel surveillance system has provided data on the pattern of SARS-CoV-2 outbreaks among 45 LTCFs in South Africa. From April 2020 to July 2021, 15 LTCFs reported one outbreak and 24 reported two or more outbreaks; of those that reported an outbreak, $10(25.6 \%)$ reported small outbreaks and 29 (64.4\%) reported large outbreaks. This analysis has revealed a decreasing trend in the numbers of SARS-CoV-2 outbreaks and cases in LTCFs over the course of the epidemic, with the highest risk of mortality occurring in the very early weeks of the epidemic.

Outbreaks were more frequently reported during the first COVID-19 wave, and the numbers of cases among LTCFs were lower in the second and third waves. This is notable given that the second wave in South Africa was associated with more cases and deaths and higher in-hospital CFR than the first wave. ${ }^{15}$ Other countries have similarly reported fewer cases, deaths and CFR in LTCFs in the second wave. ${ }^{12,16}$ This is ascribed to improved control measures and shielding of vulnerable people. Firstly, there was greater awareness of fatality risks among the vulnerable LTCFs residents. Secondly, efforts were put in place to protect LTCFs as learned from experience during the first wave of COVID-19 in nursing homes. Thirdly, improved routine hygiene measures, infection control, testing of personnel and residents, and avoidance of staff working across multiple nursing homes were implemented during the second wave. ${ }^{17}$

The CFR amongst residents with highest risk in old age homes (18\%) and frail care centres (13\%), was lower than rates reported in other studies. ${ }^{18}$ The residents in these settings were likely older and had comorbidities which are known risk factors for COVID-19 mortality. A review of COVID-19 in LTCFs reported an average mortality rate of $21 \%{ }^{2}$ A population-based analysis of LTCFs in the United Kingdom, reported a case fatality ratio of $48 \% .{ }^{17}$ The pooled mortality rate in the first three months of the pandemic amongst LTCFs in Spain was $28 \%,{ }^{19}$ In a cohort study of SARS-CoV-2 cases in LTCFs in the UK, $10 \%$ of residents and $5 \%$ of staff were infected with a CFR in residents of $36 \% .{ }^{20}$ Another study in the US involving 30 LTCFs, reported a CFR among residents of $34 \% .{ }^{21}$ These studies reported high CFR in the first few months of the pandemic; our average CFR estimate was lower for the study period over 17 months.

One of the risk factors for mortality among LTCFs residents was age over 40 years. Older age, male sex and the presence of comorbidities such as hypertension, diabetes, chronic cardiac and renal diseases, malignancy, HIV and TB, as well as obesity, have been described as risk factors for COVID-19 mortality in meta-analyses and from a large national surveillance system in South Africa. ${ }^{10,22,23}$

There highest risk of mortality amongst LTCFs in the early weeks of the epidemic. One contributing factor may be improved preparedness, treatment and case management over time. ${ }^{24}$ LTCFs did not have increased mortality in the second and third waves predominated by the Beta and Delta variants respectively. This is in contrast to the increased in-hospital mortality reported in the second wave compared to the first wave in South Africa possibly related to the circulation of the Beta variant which predominated during the second wave. ${ }^{15}$ 


\section{Strengths And Limitations}

We could not find any other studies in Africa describing SARS-CoV-2 in LTCFs. DATCOV is a sentinel surveillance system that has only a small number of reporting sites for LTCFs which may not be generalizable across the country, but it does include sites in most provinces and across different LTCF types. There is some incomplete data in the surveillance system, particularly that of smoking $(1,348 / 2,324,58.0 \%)$. These variables have therefore been excluded from the multivariable analysis.

\section{Conclusion}

While studies from developed countries have reported that infection control interventions, such as universal testing of staff and residents, were effective in mitigating COVID-19 outbreaks ${ }^{3}$, these strategies are unlikely to be feasible in LMIC settings. The analysis in sentinel LTCFs in South Africa, the only study of its kind to our knowledge in Africa, points to an encouraging trend of decreasing number of SARS-CoV2 outbreaks, cases and CFR from the first to the third waves. LTCFs are likely to have learnt from international experience and adopted national protocols, which include improved measures to limit transmission and administer appropriate clinical care.

\section{List Of Abbreviations}

CFR Case Fatality Ratio

COVID-19 Coronavirus Disease 2019

HIV Human Immunodeficiency Virus

IQR Inter Quartile Range

LMIC Low- and Middle-Income Countries

LTCF Long-term Care Facility

NICD National Institute for Communicable Diseases

RT-PCR Real Time Polymerase Chain Reaction

SARS-CoV-2 Severe Acute Respiratory Syndrome Coronavirus Two

TB Tuberculosis

WHO World Health Organization

\section{Declarations}




\section{Ethics approval and consent to participate}

The data used for this study were de-identified to ensure confidentiality. All personal information of the residents and staff, concerning health status, treatment or stay in a health establishment, were kept confidential and stored in a secure server. For analysis, patient identifiers were de-linked from other data and stored separately. Ethical approval for this study was obtained from the University of the Witwatersrand Human Research Ethics Committee (M160667).

\section{Consent for publication}

Consent for publishing this data was granted by Dr Waasila Jassat and the National Institute for Communicable Diseases.

\section{Availability of data and materials}

The datasets generated and/or analysed during the current study are not publicly available due to patient/participant confidentiality but are available from the corresponding author on reasonable request. Data are securely stored on the DATCOV surveillance system and is available upon request.

\section{Competing interests}

There are no competing interests for this study.

\section{Funding}

DATCOV is funded by the National Institute for Communicable Diseases (NICD) and the South African National Government. No additional funding was obtained towards the completion of this analysis and the development of this manuscript.

\section{Authors' contributions}

TA, BC, WJ, LG, LB and MM contributed to conception of the manuscript. TA, WJ, MM, CC contributed to study design and data collection. TA, ST, WJ contributed to data analysis, and creation of tables and figures. WJ, MM, BC, CC, TK, SW, LB and TA contributed to data interpretation and writing. TA, WJ, BC and MM drafted the manuscript and all other authors contributed scientific inputs equally to drafts of the manuscript. ST, TR, DC, AH, WJ, CC, MM and BC critically reviewed the manuscript. All authors approved the submitted version of this study.

\section{Acknowledgements}

To preserve anonymity, we have not included names of LTCFs. We thank and acknowledge all 45 LTCFs that voluntarily submitted data to DATCOV. We also acknowledge the Department of Health, Department of Social Development at national and provincial levels, and the DATCOV web-developers, ComUnity. 
The DATCOV team are acknowledged for their hard work and dedication, including Richard Welch, Rebone Kai, Noel Mfongeh, Monwabisi Blom, Felicia Malomane, Kholofelo Skosana, Salaminah Mhlanga, Lovelyn Uzougwu, Caroline Mudara, Caroline Vika, Murray Dryden, Busisiwe Manzini, Linamandla Qekeleshe, Siphamandla Mzobe, Yongama Mangwane, Mami Mokgosana, Thobile Buthelezi and Portia Makwene.

\section{References}

1. Thompson DC, Barbu MG, Beiu C, Popa LG, Mihai MM, Berteanu M, Popescu MM. The Impact of COVID-19 Pandemic on Long-Term Care Facilities Worldwide: An Overview on International Issues. Hindawi Volume 2020, Article ID 8870249, 7 pages https://doi.org/10.1155/2020/8870249

2. Lau-Ng R, Caruso L, Perls T. COVID -19 Deaths in Long-Term Care Facilities: A Critical Piece of the Pandemic Puzzle. Journal of the American Geriatrics Society. 2020;68(9):1895-1898.

3. Gmehlin C, Munoz-Price L. Coronavirus disease 2019 (COVID-19) in long-term care facilities: A review of epidemiology, clinical presentations, and containment interventions. Infection Control \& Hospital Epidemiology. 2020;1-6.

4. Aday LA. Who are the vulnerable? In: At Risk in America: The Health and Health Care Needs of Vulnerable Populations in the United States. 2nd ed. San Francisco, Calif: Jossey-Bass; 1991:1-15.

5. Towards long-term care systems in sub-Saharan Africa: WHO series on long-term care. Available from https://www.who.int/ageing/long-term-care/WHO-LTC-series-subsaharanafrica.pdf

6. The Government of South Africa: Old age pension. Available from: https://www.gov.za/services/social-benefits-retirement-and-old-age/old-age-pension\#

7. Ashwell A, Jacobs R, Docrat S \& Schneider M. (2020) The impact of Covid-19 on long-term care facilities in South Africa with a specific focus on dementia care. LTCcovid.org, International LongTerm Care Policy Network, CPECLSE, 10 July 2020

8. National Institute for Communicable Diseases. Covid-19 weekly epidemiology brief. [cited 14 April 2021]. Available from: nicd.ac.za/wp-content/uploads/2021/04/COVID-19-Weekly-EpidemiologyBrief-week-15-2021.pdf *

9. Definitions care homes: Apps.who.int. 2021 [cited 25 May 2021]. Available from: https://apps.who.int/iris/bitstream/handle/10665/178879/9789241565011_eng.pdf?sequence=1

10. Mesas A, Cavero-Redondo I, Álvarez-Bueno C, Sarriá Cabrera M, Maffei de Andrade S, SequíDominguez I et al. Predictors of in-hospital COVID-19 mortality: A comprehensive systematic review and meta-analysis exploring differences by age, sex and health conditions. PLOS One. 2020;15(11):e0241742

11. Definitions substance abuse recovery centre: Internet [cited 25 May 2021]. Available from: https://www.rehabs.com/treatment/rehab/

12. Shallcross L, Burke D, Abbott O, Donaldson A, Hallatt G, Hayward A et al. Factors associated with SARS-CoV-2 infection and outbreaks in long-term care facilities in England: a national cross- 
sectional survey. The Lancet Healthy Longevity. 2021;2(3):e129-e142.

13. National Institute for Communicable Diseases. Covid-19 weekly epidemiologic brief. 2021 [cited 4 October 2021]. Available from: https://www.nicd.ac.za/wp-content/uploads/2021/09/COVID-19Weekly-Epidemiology-Brief-week-38-2021.pdf

14. World Health Organization (WHO). International Guidelines for Certification and Classification (Coding) of COVID-19 as cause of Death: based on ICD International Statistical Classification of Diseases (16 April 2020). Geneva: WHO; 2020 [22 April, 2020]. Available from: https://www.who.int/classifications/icd/Guidelines_Cause_of_Death_COVID19.pdf?ua=1

15. Jassat W, Mudara C, Ozougwu L, Tempia S, Blumberg, Davies MA et al. Difference in mortality among individuals admitted to hospital with COVID-19 during the first and second waves in South Africa: a cohort study. The Lancet. https://doi.org/10.1016/S2214-109X (21)00289-8

16. Ioannidis J, Axfors C, Contopoulos-loannidis D. Second versus first wave of COVID-19 deaths: Shifts in age distribution and in nursing home fatalities. Environmental Research. 2021;195:110856

17. Burton JK, Bayne G, Evans C, Garbe F, Gorman D, Honhold N, et al. 2020. Evolution and effects of COVID-19 outbreaks in care homes: a population analysis in 189 care homes in one geographical region of the UK. The Lancet Healthy Longevity 1 (1), e21-e31.

18. Dean A, Venkataramani A, Kimmel S. Mortality rates from COVID-19 are lower in unionized nursing homes. Health Affairs. 2020;39(11):1993-2001

19. Mas Romero M, Avendaño Céspedes A, Tabernero Sahuquillo M, Cortés Zamora E, Gómez Ballesteros C, Sánchez-Flor Alfaro V et al. COVID-19 outbreak in long-term care facilities from Spain. Many lessons to learn. PLOS ONE. 2020;15(10):e0241030.

20. Dutey-Magni P, Williams H, Jhass A, Rait G, Lorencatto F, Hemingway H et al. COVID-19 infection and attributable mortality in UK care homes: cohort study using active surveillance and electronic records (March-June 2020). Age and Ageing. 2021;50(4):1019-1028.

21. McMichael T, Currie D, Clark S, Pogosjans S, Kay M, Schwartz $N$ et al. Epidemiology of Covid-19 in a Long-Term Care Facility in King County, Washington. New England Journal of Medicine. 2020;382(21):2005-2011.

22. Shi S, Bakaev I, Chen H, Travison T, Berry S. Risk factors, presentation and course of coronavirus disease 2019 in a large, academic long-term care facility. Journal of the American Medical Directors Association. 2020;21(10):1378-1383.e1.

23. Jassat W, Cohen C, Tempia S, Masha M, Goldstein S, Kufa T et al. Risk factors for COVID-19-related in-hospital mortality in a high HIV and tuberculosis prevalence setting in South Africa: a cohort study. 2021. The Lancet HIV; https://doi.org/10.1016/ S2352-3018(21)00151-X

24. Horby P, Lim WS, Emberson JR, Mafham M, Bell JL, Linsell L, et al. 2020. Dexamethasone in hospitalized patients with covid-19 - preliminary report. 2021. N. Engl. J. Med. Feb 25;384(8):693704. doi: 10.1056/NEJMoa2021436. Epub 2020 Jul 17. PMID: 32678530

\section{Figures}




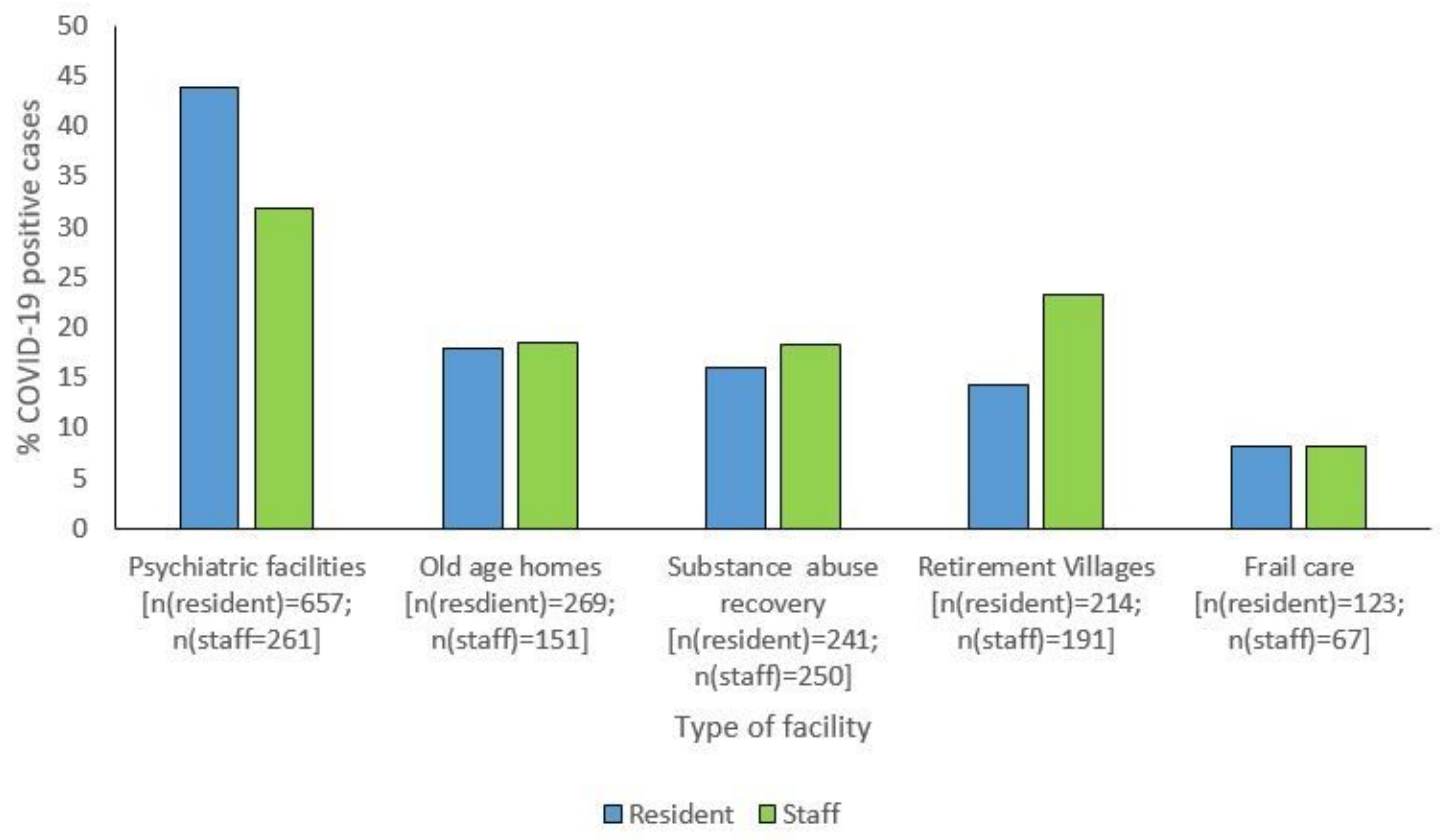

Figure 1a.

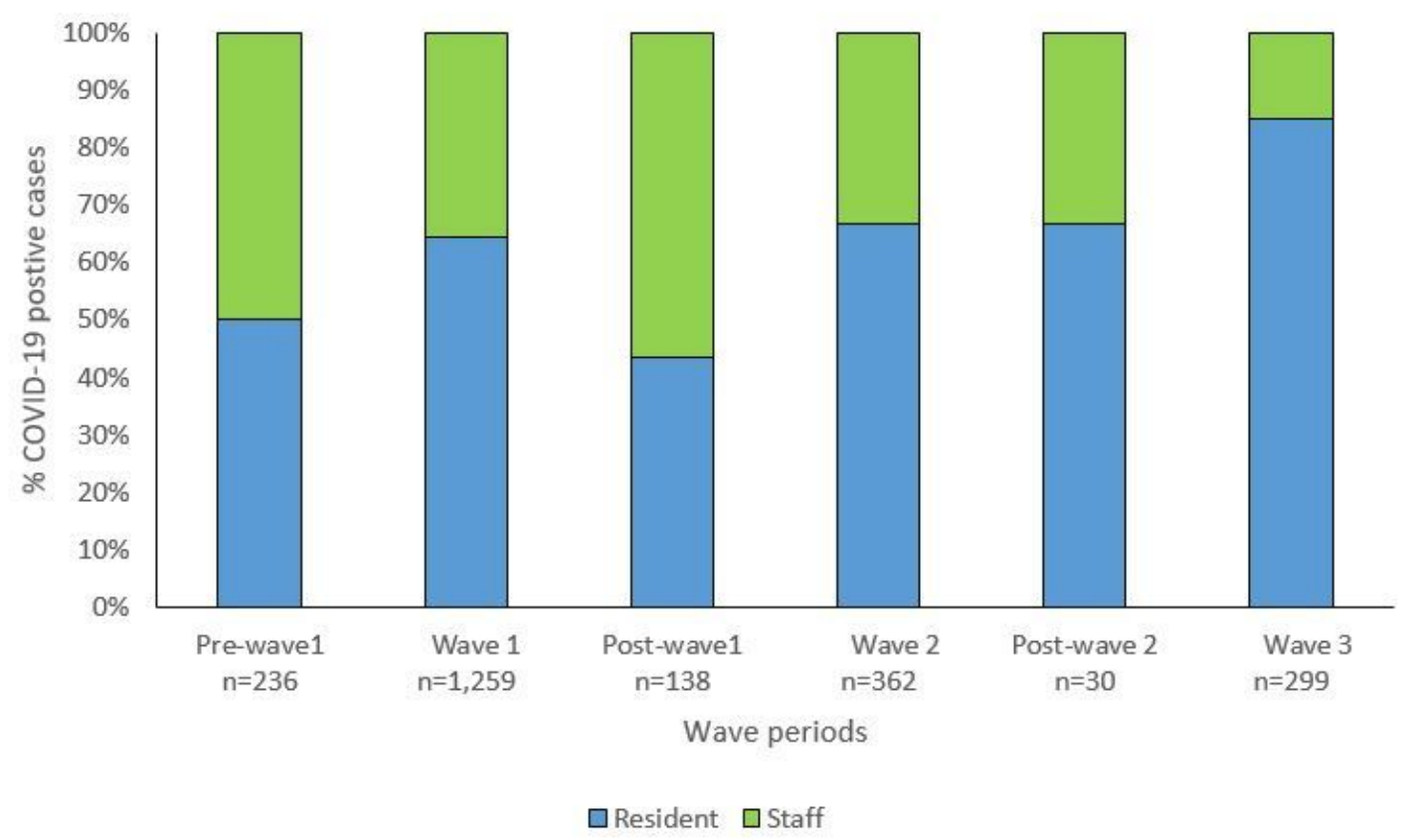

Figure 1b.

\section{Figure 1}

1a. Proportion of SARS-CoV-2 infected LTCF residents and staff per facility type, South Africa, 5 March $2020-31$ July 2021, n=2,324. 1b. Proportion of LTCFs resident and staff infected with SARS-CoV-2 5 March 2020 - 31 July, 2021 

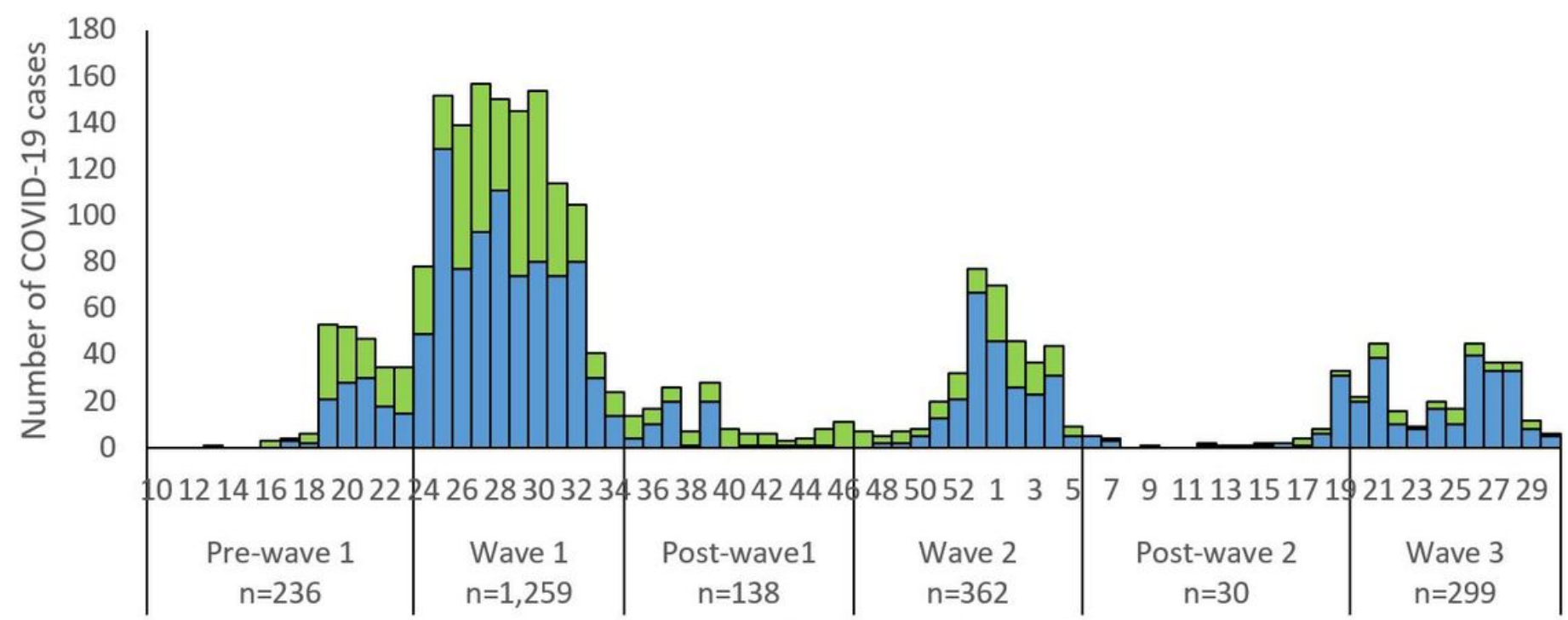

Epidmiologic week of diagnosis

$\square$ Residents $\square$ Staff

\section{Figure 2}

Number of SARS-CoV-2 cases in care homes by epidemiologic week, 5 March 2020 - 31 July 2021, South Africa, $n=2,324$.
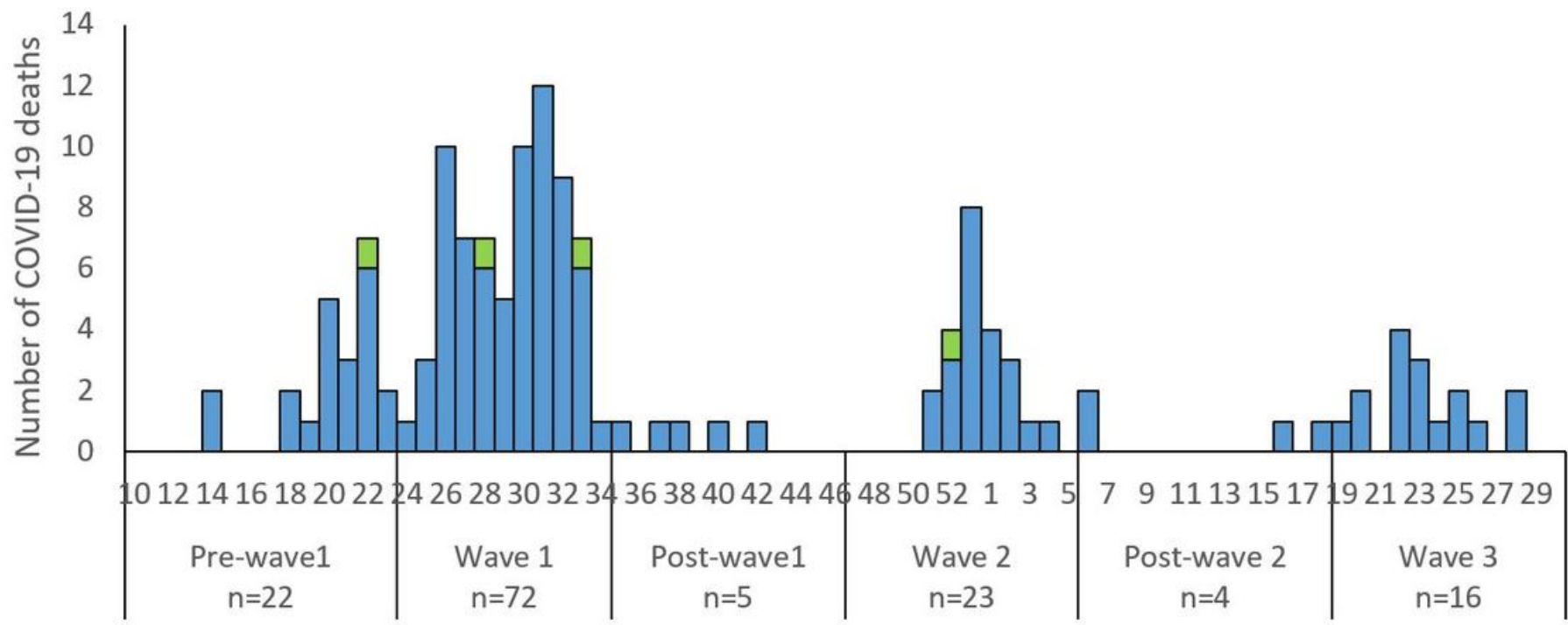

Epidemiologic week of outcome

$\square$ Resident $\square$ Staff

\section{Figure 3}


Numbers of COVID-19 deaths reported per week among residents and staff, by epidemiologic week, South Africa, 5 March 2020 - 31 July 2021, ( $n=142)$.

\section{Supplementary Files}

This is a list of supplementary files associated with this preprint. Click to download.

- Supplementarymutipanelfiguressubmission.docx 